\title{
O JUDICIÁRIO BRASILEIRO E A INTERVENÇÃO NAS POLÍTICAS PÚBLICAS DE SAÚDE
}

\author{
Claudio Ruiz Engelke ${ }^{1}$ \\ José Ricardo Caetano Costa ${ }^{2}$
}

\section{Resumo}

Pretende-se, neste artigo, analisar o fenômeno chamado de judicialização da saúde, em que ações judiciais pleiteiam alguma medida do sistema estatal. Para tanto será analisada a saúde como política pública, a sua evolução histórica e a avaliação do contexto atual de redução orçamentária e fenômeno de medicalização da vida. Com isso se observa a situação da saúde pública no Brasil para compreender as razões da atuação do judiciário bem como os efeitos que esta intervenção provoca no sistema público.

Palavras-chave: Saúde, Judicialização, Poder Judiciário, Justiça social.

\section{THE BRAZILIAN JUDICIAL BRANCH AND THE INTERVENTION IN PUBLIC HEALTH POLICIES}

\begin{abstract}
In this article, we intend to analyze the phenomenon called health judicialization, in which lawsuits claim some measure of the state system. In order to do so, it will analyze health as a public policy, its historical evolution and the evaluation of the current context of budget reduction and the phenomenon of medicalization of life. This analyzes the public health situation in Brazil in order to understand the reasons for the judicial branch and the effects of this intervention on the public system
\end{abstract}

\footnotetext{
${ }^{1}$ Mestrando no Programa de Pós Graduação em Direito e Justiça Social da Faculdade de Direito da Universidade Federal do Rio Grande - FURG. E-mail: claudioengelke@msn.com

${ }^{2}$ Mestre em Direito, Doutor em Serviço Social e Professor do Programa de Pós Graduação em Direito e Justiça Social da Universidade Federal do Rio Grande (FURG). E-mail: jrcc.pel@gmail.com
} 
Keywords/Palabras-claves/Mots-clés: Health, Judiciary, Judicial branch, Social justice.

\section{INTRODUÇÃO}

Pretende-se, com o presente artigo analisar o fenômeno que se tornou bastante recorrente e que passou a ser denominado de "judicialização da saúde", e a forma como a interferência do Poder Judiciário nas políticas públicas direcionadas à saúde pode prejudicar a atuação do Estado no âmbito dos direitos sociais.

Com efeito, as políticas públicas em saúde no Brasil sofrem uma série de dificuldades, e entre elas se destaca a exagerada intervenção através de ordens judiciais que buscam garantir medidas aos jurisdicionados, o que resolve situações específicas, mas desorganiza o sistema público e prejudica quem mais necessita. Mas esta questão é bastante complexa e alguns pontos devem ser analisados para que se tenha compreensão desta situação.

Em primeiro lugar, deve se considerar que a atuação estatal para garantir a saúde pública no Brasil é relativamente recente. Além disso, ao se pensar em políticas públicas voltadas para a saúde deve-se sempre levar em consideração a existência de um marco divisório que foi o advento do Sistema Único de Saúde. A crise que o sistema enfrenta é agravada por fatores como a redução orçamentária através do congelamento de gastos públicos por 20 anos, determinada pela Emenda à Constituição no 95/2016, que instituiu o chamado "Novo Regime Fiscal", bem como a cultura da medicalização para todos os males da população, que imprime no meio social a lógica imposta pelo mercado farmacêutico e que acabam agravando ainda mais a crise, que é ainda mais acirrada a judicialização da saúde.

A crise no sistema público de saúde impede que o Estado consiga cumprir com a função de proteger e oferecer tratamentos terapêuticos para a população, fazendo com que seus usuários recorram ao Poder Judiciário para que este supra as carências que os órgãos responsáveis não conseguem dar uma resposta. Com isso cria-se um fenômeno social que é chamado de judicialização da saúde, que desorganiza e acaba reduzindo a capacidade de atuação estatal de implementar as políticas públicas.

Esta forma de adequar a necessidade individual ao que determina a Constituição desconsidera a lógica adotada para o sistema público, e que gera a desorganização da administração da saúde pública e a escassez de recursos na área. 


\section{A saúde como política pública}

A saúde como área que integra a seguridade social e que busca o bem estar físico, mental e social, no âmbito nacional, reflete a realidade do país. Os serviços que visam a saúde dos cidadãos podem ser privados, com excelentes hospitais, referências mundiais, ótimos profissionais e que está disponível para uma pequena parte da população, e que não é objeto do presente estudo. Existe também a saúde pública, coordenada pelo Sistema Único de Saúde SUS, e que atende grande parte do contingente de pessoas, que é resultado de uma política pública, e que é o tema central da pesquisa.

Para que se possa pensar em políticas públicas é indispensável saber de onde surgiu esta forma de atuar em que o Estado interfere concedendo benefícios para os cidadãos e com isso impulsiona a economia. A atuação estatal através de políticas públicas é reativamente recente na história.

Como forma de garantir o bem-estar dos cidadãos, os Estados modernos adotam políticas públicas que visam garantir condições mínimas necessárias. Esta forma de atuação varia de país para país, sofrem alterações com o tempo, com a ideologia daqueles que detêm o poder, com situações econômicas e sociais específicas, com condições climáticas e ambientais, etc.

Esta forma de ver o Estado como uma entidade que serve à população é relativamente recente e tem como marcos as revoluções na América do Norte e na França. A tripartição do poder estatal, com meios democráticos de escolha de autoridade deu a forma para as estruturas que hoje os Estados modernos possuem.

A ideia que o Estado deve manter políticas públicas que garantam a seguridade social, na qual se inclui prestações em saúde, foi bastante disseminada no capitalismo ocidental após a segunda guerra. A quebra da bolsa de 1929 já havia demonstrado que as crises do capitalismo são cíclicas, e como forma de resguardar a economia e criar um meio de amortecer as quedas econômicas foi apresentado pelo economista britânico John Maynard Keynes uma nova forma de organização da sociedade, em que o Estado atua diretamente na economia através da criação e manutenção de políticas sociais. Foi uma resposta ao modelo até então vigente que defendia 
o liberalismo clássico, do livre mercado que acreditava que o próprio mercado, através de mecanismos próprios iria regulamentá-lo.

Esta teoria econômica chamada de keynesianismo defende que o Estado deve garantir que a população tenha ao menos o mínimo necessário para poder existir com dignidade, e esta garantia é garantida através de benefícios sociais. A forma como estas medidas de proteção sociais são distribuídas depende de como cada Estado se organiza para decidir onde os investimentos serão aplicados. Como exemplo, a forma como investimentos em determinada área social deve ser aplicada,se de uma forma ou de outra, se a educação deve ser universal ou se não, a forma como a previdência social é regida, ou se a questão racial será ou não considerada para que o cidadão ingresse no serviço público.

Com isso se percebe que para a escola keynesiana a atuação estatal é crucial para que os benefícios sociais atinjam seus objetivos, e para que isto ocorra é necessário que exista uma organização para distribuição conforme as necessidades e peculiaridades de cada sociedade. Esta forma de organização estatal para distribuição destes benefícios são as chamadas políticas públicas.

Através da aplicação de políticas públicas que concedam materialmente o mínimo necessário para que os cidadãos possam viver dignamente é que a sociedade chega ao estado de bem-estar social (welfare state), o qual fará com que a economia possa prosperar e com isso reduzir os efeitos das crises.

Esta forma de atuação estatal na economia, que auxiliou a reestruturação econômica americana nos anos 1930, foi no pós-guerra exportada e aplicada nos países europeus, recém dizimados e carentes de estrutura estatal, e sob a ameaça vizinha do comunismo.

Foi com políticas públicas que o lado ocidental do continente europeu começou a se reorganizar para que fosse possível voltar a se desenvolver economicamente bem como para barrar a ameaça oriental do lado socialista.

Através das atuações de governos que acreditaram que investir em políticas sociais para suprir as necessidades dos cidadãos que o conceito de políticas públicas foi criado e pode se desenvolver.

Com isso se percebe que não há como dissociar o estudo e a análise de qualquer política pública sem que se perceba a atuação estatal, sem que se tenha como meta o estado de bemestar. 
Ocorre que ao mesmo tempo em que o keynesianismo era desenvolvido em vários países, em especial no continente europeu, com suas políticas de bem-estar social, surgia um movimento que se apresentava como um contraponto ao welfare state, uma proposta que tinha como fundamento a redução absoluta da atuação estatal, e como consequência, e que visava redução do Estado.

Este movimento que ficou mais conhecido como neoliberalismo, mas também chamado de neoconservadorismo, teve seu marco inicial em um encontro de economistas na cidade de Mont Pèlerin, na Suíça, ainda em 1947, embora seus efeitos tenham efeitos práticos tenham surgido somente nos anos 1970, quando passou a ser considerado um movimento hegemônico com as experiências na Inglaterra de Margaret Thatcher e nos Estados Unidos, de Ronald Reagan. Desde então esta visão econômica que buscava redução drástica do Estado e fim das políticas sociais foi se espalhando pelo globo, e no início dos anos 1990 chagou ao Brasil.

Compreende-se, assim, que a realização de políticas públicas está diretamente relacionada com a forma política e econômica que cada Estado tem interesse em adotar. Em um país cuja política está voltada para o desenvolvimento da economia de mercado, de apoio às teorias neoconservadoras, as políticas públicas são muito reduzidas, ou até mesmo inexistentes para a maioria da população. Já em um contexto de um Estado em que a política busca soluções através do estado de bem-estar social, pode-se observar que as políticas públicas são tratadas como uma política de Estado.

\footnotetext{
A concepção de mundo trazida pelos neoconservadores, por sua vez, é bem distinta daquela defendida pelos liberais. Segundo seu entendimento, o colapso do Estado do Bem-Estar Social deveu-se ao excesso de intervenção do Estado, bancando políticas públicas com dispêndio significativo do erário público. Profetizam que o capitalismo não está em crise, sendo esta a falta de capitalismo, e não seu excesso. (COSTA, 2015, p. 85)
}

Neste contexto se compreende que a alteração de comando na política, e consequentemente na economia do Brasil pode fazer com que as políticas públicas surjam, se o governo tiver uma conotação estatizante, ou desapareçam, em um contexto de um governo de características privatistas.

As políticas públicas na área da saúde acompanham a forma como o Estado é desenhado e refletem a intenção dos governantes. Assim, não é por acaso que há uma enorme dívida do 
Estado brasileiro com uma parcela enorme da população, que não teve acesso a políticas de saúde. Mas para que se possa falar em políticas públicas na saúde, é importante a análise acerca do desenvolvimento da saúde pública no Brasil.

\subsection{A origem da saúde pública no Brasil}

A saúde pública no Brasil, até a vinda da família real portuguesa para o Brasil em 1808 era inexistente, portanto pode-se afirmar que as políticas públicas neste setor possuem um marco histórico, e que data de aproximadamente duzentos anos.

Até então a população era acometida por doenças tipicamente tropicais e desconhecidas pela comunidade científica da época, como a malária e a febre amarela, bem como enfermidades que foram trazidas pelos colonizadores como varíola, cólera e peste bubônica. Haviam poucos conhecimentos para tratar questões de saúde, pois eram desconhecidas as formas de transmissão, controles e tratamentos das doenças. Evidente que a mortalidade era muito alta, já que praticamente inexistente a presença de médicos e demais profissionais da área de saúde.

\footnotetext{
Existia o barbeiro ou prático, um conhecedor de algumas técnicas utilizadas pelos médicos europeus, tais como as sangrias, que atendia à população capaz de remunerálo. Existiam os curandeiros e pajés, pertencentes à cultura negra e indígena, mais acessíveis à maioria da população, que se utilizavam das plantas, ervas, rezas e feitiços para tratar os doentes. Havia também os jesuítas, que traziam algum conhecimento da prática médica europeia utilizando-se principalmente da disciplina e do isolamento como técnica para cuidar dos doentes. (BAPTISTA, 2007, p. 31)
}

Somente com a expulsão da corte de Portugal pelo exército de Napoleão que esta aportou no Brasil e trouxe uma série de inovações científicas, sempre com o fim de manter a mão de obra e proporcionar um ambiente para que a nação pudesse se desenvolver. Com a vinda da corte portuguesa foi possibilitada a entrada de mais médicos e o aumento da preocupação com as condições de vida da população local, "possibilitando o início de um projeto de institucionalização do setor da saúde no Brasil e a regulamentação da prática médica profissional" (FLORES, 2016, 126). Ainda em 1808 foi inaugurada a Escola médico-cirúrgica de Salvador, e o ensino da medicina foi institucionalizado e padronizado.

Na primeira República (1889-1930) o movimento sanitarista expôs situação da saúde pública como uma questão social e política. Houve a ampliação do Estado e a criação do alicerce da saúde pública. 


\begin{abstract}
Na Primeira República, o movimento sanitarista demonstrou a situação da saúde como um a questão social e política e era o maior obstáculo à integração do Brasil ao mundo civilizado. Como consequência, ocorreu a expansão da autoridade estatal sobre o território, ao mesmo tempo em que se criavam os fundamentos para a formação da burocracia da saúde pública (FLORES, 2015, p.126)
\end{abstract}

Em 1903, o médico especialista em microbiologia Oswaldo Cruz é nomeado diretor geral de saúde pública no governo de Rodrigues Alves e começa a reforma da saúde. No ano seguinte propõe o código sanitário, considerado na época um código de torturas em razão da rigidez das ações que eram propostas.

A atuação do mais impactante do referido sanitarista foi a instituição da campanha da vacinação obrigatória. Procedimento novo que diante da população sem informações causou muita contrariedade, vindo a culminar no movimento chamado de Revolta da Vacina. Apesar das contrariedades, sua atuação pode ser considerada exitosa no controle de algumas moléstias, tanto que houve avanços na erradicação de uma série de enfermidades. "Em 1907 a febre amarela e outras doenças já tinham sido erradicadas da cidade do Rio de Janeiro e Belém”. (BAPTISTA, 2007, p.34).

A segunda fase do movimento sanitarista (1910 e 1920), Cruz intensificou o saneamento rural e realizou incursões pelo interior, e foi possível comprovar a necessidade de uma política pública na área da saúde. "As expedições revelaram um Brasil doente e suscitaram o questionamento do discurso romântico sobre os sertões como espaço saudável”. (BAPTISTA, 2007, p.34)

Com o advento da Lei Eloy Chaves, em 1923, foram criadas as Caixas de Aposentadorias e Pensões, conhecidas como CAPs, que atuavam como seguro social para categorias profissionais, e que prestavam serviços de saúde.

No governo de Getúlio Vargas foram criados os Institutos de Aposentadorias e Pensões, IAPs, "o primeiro passo para a organização de nosso sistema de previdência e seguridade social". (COSTA, 2013, p. 101)

No período da ditadura e várias alterações na esfera administrativa ocorreram. Em 1966 os IAPs deram origem ao Instituto Nacional de Previdência Social (INPS). No começo dos anos de 1970, a política adotada pelo do INPS “levou à inclusão de novas categorias profissionais no sistema trabalhadores rurais, empregadas domésticas e autônomos e com a inclusão de novas 
categorias, aumentava a procura por serviços e os gastos no setor de saúde”. (FLORES, p.128, 2015).

Em 1986 ocorreu a $8^{\circ}$ Conferência Nacional de Saúde, onde foi criado o Sistema Único e Descentralizado e Saúde (SUDS), que teve papel crucial para a implantação do SUS em 1987.

Foi com a Constituição de 1988 que o SUS passou a figurar inserido na seguridade social em conjunto com a previdência e assistência social. Foram então garantidos os princípios da universalidade e igualdade de acesso aos serviços do SUS. As regras para adoção de um sistema único foram aprimoradas e em 1990 foi editada a Lei 8.080/90, que regulamentou a forma de atuação deste sistema considerado o maior do mundo.

A forma de atuação do SUS está baseada em dois princípios fundamentais: a universalidade e igualdade de cobertura e do atendimento, que visam garantir que todo cidadão, sem a interferência de qualquer espécie de privilégio ou impedimento, deve ter acesso aos serviços de saúde públicos e privados conveniados. A lógica adotada para a prestação deste serviço foi de uma rede de serviços hierarquizada, do menor nível de complexidade para o maior, com as correspondentes tecnologias. "Todo o cidadão é igual perante o SUS e será atendido conforme suas necessidades até o limite que o sistema pode oferecer para todos". (FLORES, 2016, p 128).

O Sistema de saúde pública brasileiro teve como referência o padrão adotado no Reino Unido. O Sistema Nacional de Saúde britânico - National Helth Service (NHS) - que é um dos mais eficientes e maiores serviços de saúde púbica do mundo, além de ser o mais antigo, pois foi criado no período pós-guerra (1948), e serviu como paradigma para a criação de um sistema inovador em países de características continentais como o Brasil. A ideia de universalidade advém deste sistema de saúde britânico, que possui relação estreita com o conceito de solidariedade consagrado na Constituição. "Muitos asseveravam que o sistema de saúde do Reino Unido havia servido de modelo ao nosso, principalmente por adotar os mesmos princípios básicos definidores: universalidade, integralidade e gratuidade”. (TANAKA e OLIVEIRA, 2007).

\subsection{A saúde pública brasileira hoje}


A Constituição Federal de 1988 buscou implementar o Estado de bem-estar social no Brasil e conferiu saúde gratuita para todos, educação pública como um dever dos governantes, bem como assistência social aos necessitados.

Ocorre que assim como qualquer política pública, a saúde também possui um custo financeiro e, portando, depende da disponibilidade do orçamento. "Dos anos 1990 aos dias atuais, a questão do financiamento se traduz em inúmeras dificuldades, conflitos e obstruções no seu processo de implementação" (SENNA e MONNERAT, 2010, p. 197)

A forma como o orçamento público é manejado pelos chefes de Poderes Executivos diz muito sobre a intenção do Estado. Com o movimento da economia mundial de se alinhar às intenções do neoconservadorismo, as leis orçamentárias começaram a seguiram esta tendência, e os cortes em áreas vinculadas aos direitos sociais também passaram a ser comuns.

Um grande obstáculo ao desenvolvimento de várias políticas públicas, e que prejudicará consideravelmente a saúde pública foi a alteração no texto constitucional através da Emenda à Constituição $n^{\circ}$ 95/2016, que fixou o chamado "Novo Regime Fiscal" e que limita através do congelamento dos gastos públicos por vinte anos.

Com a medida, todas as despesas públicas serão corrigidas do orçamento de um ano para o seguinte somente levando em consideração a taxa de inflação oficial - Índice Nacional de Preços ao Consumidor Amplo (IPCA), de forma que impede o aumento real. Os itens saúde e educação sofrerão a incidência desta nova lógica em 2018, um ano depois que as demais despesas públicas, já que foram contemplados com uma distinção de ter a aplicação da regra somente depois do primeiro ano.

Desta forma, se antes deste teto orçamentário a situação da saúde pública brasileira já não era aquela esperada pela população, e não conseguia atingir os objetivos propostos na Constituição, agora com esta referida limitação orçamentária será ainda mais difícil oferecer à população uma política de saúde pública. Com os recursos cada vez mais escassos e com menos serviços de saúde, a tendência é que ocorra um aumento considerável no número de ação judiciais pleiteando que o sistema público atue de alguma forma na prestação de serviços de saúde.

Mas evidente que um problema dentro de um universo tão vasto como a saúde pública no Brasil não encontra uma causa, mas são muitas as variáveis que fazem com que as políticas 
em saúde tenham adquirido a conformação atual. E uma das formas de interferência na saúde é o modo de agir e de pensar da população, e que tem reflexo nas políticas públicas.

Outro fator que pode ser considerado um agravante da situação da saúde pública no Brasil é a forma como a sociedade atual se comporta no que se refere a saúde. Existe um fenômeno social que é impulsionado por necessidades do capitalismo e impostas pelo mercado “acaba ganhando considerável projeção nesse tipo de economia que estimula o consumo desenfreado de medicamentos" (BRAUNER e FURLAN, 2016, p.44).

A medicalização da vida é um processo que vem ocorrendo em grande parte dos países ocidentais, e decorre da forma como se constitui a economia de mercado global. Este fenômeno encontra solo fértil em sociedade composta por muitos cidadãos carentes de senso crítico e de responsabilidade, e que acabam por incorporar a dinâmica que os mercados de medicamentos impõem.

A forma de agir e pensar de grande parcela da população é conduzida para uma verdadeira cultura do adoecimento, em que é depositada uma confiança quase cega na tecnologia desenvolvida pela indústria farmacêutica.

A criação de novas técnicas de tratamento, o desenvolvimento de novos fármacos, a formulação de novas especialidades médicas, em sintonia com as exigências mercadológicas, são formas de obter aumento de faturamento para quem domina este mercado. Para que estas novidades tenham aceitação estas são sempre atreladas a inovações tecnológicas. Um medicamento passa a ser confiável na medida em que é desenvolvido e aprovado por quem detém o poder da ciência, ainda que esteja totalmente envolvido com a indústria farmacêutica.

Com isso é perceptível na sociedade atual que quando há a intenção de legitimar uma descoberta, conferir credibilidade a uma nova técnica, a primeira atitude realizada é a associação com a ciência, e isto ocorre na área da saúde com em todas as áreas do conhecimento.

\footnotetext{
Afinal, a ciência herda o prestígio da religião no contexto pré-moderno e assume, em boa parte, pelo menos, o papel de explicar o mundo moderno. Não existe tema que seja discutido na esfera pública de qualquer sociedade moderna que não invoque a "palavra do especialista" que fala pela ciência. Assim, o potencial da ciência de produzir efetivo aprendizado individual e coletivo está ligado e muitas vezes decisivamente condicionado, por força de seu prestígio público, a servir de instância legitimadora e primeira e decisiva trincheira da luta social e política pela definição legítima de "boa vida" e "sociedade justa". Em outras palavras: não existe ordem social moderna sem uma legitimação pretensamente científica desta mesma ordem. (SOUZA, 2015, p. 11)
} 
A técnica é comumente associada a neutralidade, a ciência atua como algo acima de qualquer ideologia, e assim a indústria farmacêutica também usa desta forma de racionalidade para criar uma falsa ideia de ciência descompromissada com a exploração e manipulação. A falsa pureza que reveste o discurso da ciência pode ser verificada com uma conscientização ocorrida nas últimas décadas: "o desenvolvimento da técnica não provoca somente processos de emancipação, mas também novos processos de manipulação do homem pelo homem ou dos indivíduos humanos pelas entidades sociais. " (MORIN, 2010, p. 109)

Através de várias formas que a indústria possui para criar consensos e influenciar os hábitos dos cidadãos, a sociedade a cada dia se torna mais dependente dos fármacos, as pessoas acreditam em promessas de felicidade através de uma cirurgia plástica, se sentem melhores se consumirem vitaminas desnecessárias.

Ocorre que esta alteração na forma de pensar começa a apresentar a sua conta: foram criadas necessidade de mercado, que se transformam em necessidades vitais, em se tratando de saúde, e em locais onde a maioria não tem como consumir estes produtos. Com isso acaba que parte deste contingente de pessoas acaba requerendo que o Estado custeie esta nova necessidade.

Para perceber a alteração cultural que atinge o país e que altera a forma como os medicamentos e procedimentos médicos são considerados, basta ver a quantidade de anúncios publicitários de medicamentos que são veiculados diariamente, em vários veículos de comunicação. A indução à automedicação é explícita, e com a autorização do Ministério da Saúde.

Além disso, outra forma de perceber o avanço da medicalização da vida é observando a quantidade de farmácias existentes hoje nas cidades brasileiras que comercializam não apenas medicamentos, mas uma gama de produtos relacionados, também sob a influência de técnicas de comércio que estimulam bastante a automedicação.

Esta forma de consumismo que envolve a área da saúde é bastante nocivo e acaba influenciando negativamente as políticas públicas. A criação da denominada cultura do adoecimento agrava ainda mais a situação da saúde pública ante o considerável aumento das demandas judiciais com pretensões que envolvem a prestação de medidas na área da saúde. Esta situação restou demonstrada através da análise dos dados apresentados pelo Conselho 
Nacional de Justiça, que nas últimas pesquisas realizadas restou evidente o aumento deste quadro.

\section{Judicialização da saúde}

A atuação do judiciário em decisões que influenciam todos os aspectos vida social é cada vez mais observada no cenário mundial. Já faz tempo que juízes têm ocupado o espaço da política na distribuição de direitos garantidos através de políticas públicas. Determinar o limite de atuação do Judiciário frente a estas políticas é o que se propõe, de forma a delimitar o que é a função jurisdicional, de obrigar os Poderes Executivo e Legislativo a agirem e executarem a função de fazer com que políticas públicas sejam efetivadas, sem que haja uma intromissão na competência de outros poderes, e sem que se estabeleça um ativismo judicial.

Desta forma, importante destacar o estabelecimento do chamado constitucionalismo democrático, que nos tempos de welfare state dotou o judiciário de capacidade para exercer a jurisdição sobre a legislação. Com a crise do sistema de bem-estar social e com a ascensão do neoconservadorismo na economia mundial, o Estado cada vez mais esquálido retirou as amarras que mantinham direitos em vários setores sociais.

Percebe-se, desta forma, que o direito invade a política ao regular setores frágeis, com o fim de dar cobertura a aqueles que necessitam e são mais vulneráveis, tornando-se o juiz o protagonista de muitas questões sociais.

O avanço da atuação do Judiciário começa a aparecer no Brasil aparece a partir dos anos 1930, com as inovações no âmbito das relações de trabalho. Com a Constituição de 1988, elementos autoritários foram eliminados, os direitos civis da cidadania foram garantidos, e instituídos meios para a gestão pública mais eficiente para que estes direitos sejam realizados, de fato.

\subsection{A atuação do Poder Judiciário}

Ao analisar a atuação do Poder Judiciário, no que se refere às demandas envolvendo questões de saúde destaca-se, primeiro, que a saúde é dever do Estado, e é o Estado quem deve fornecer as condições para a prevenção, promoção, proteção e recuperação do estado de saúde 
de todo cidadão com dignidade, e depois que qualquer pessoa deve ter acesso ao Poder Judiciário como forma de buscar a defesa de seus direitos.

\footnotetext{
Não obstante a Constituição Federal de 1988 tenha garantido inúmeros direitos, distribuindo as competências entre os Entes Federados, além de prever meios jurídicos-processuais para garantir a efetivação desses direitos, vê-se atualmente que há uma grande falta de correspondência entre o texto legal e a realidade dos indivíduos.

Essa omissão faz com que cada vez mais se busque o Poder Judiciário para a realização dos direito constitucionalmente garantidos. (BRAUNER; CIGNACHI, 2011, p. 44).
}

Assim, o fenômeno da judicialização nos termos que se apresenta hoje é parte de um problema que emergiu do texto constitucional que garante o direito universal à saúde através de um sistema público de forma democrática, prestado através de uma estrutura estatal que não suporta a demanda exigida.

O movimento que deu início ao excesso de ações judiciais aconteceu nos anos 1990, com a descoberta de medicamentos retrovirais para prestar a fazer com que pacientes portadores do HIV tivessem acesso aos medicamentos, que na época tinham um valor bastante elevado. $\mathrm{O}$ número de ações judiciais propostas requerendo que o sistema público fosse obrigado a fornecer os medicamentos logo aumentou, e com as procedências dos pedidos e com o ingresso de ações coletivas neste sentido, o número de pacientes atendidos teve um crescimento exponencial.

Diante de situações em que o jurisdicionado tem a necessidade de uma medida em saúde, e se ele tiver a oportunidade de requerer em juízo uma medida que obrigue o poder público a lhe garantir esta medida, em uma primeira leitura, o Judiciário não pode se eximir em fazer com que seu direito seja respeitado.

A atuação do Judiciário conduzindo políticas públicas que conferem acesso a medicamentos é uma garantia do indivíduo em requerer medidas que garantam o "direito fundamental e essencial, direito este que está previsto na Carta Magna brasileira e que necessita da atuação eficaz e imparcial para atender às necessidades da população". (BRAUNER e CIGNACHI, 2011, p.30-31).

Um dos fatores decisivos para o elevado número de demandas envolvendo a saúde pública foi a posição do Judiciário em interpretar o princípio da solidariedade entre os entes federados no que tange a composição do SUS. 
A forma como a Constituição e a legislação estabeleceram a divisão de competências entre os entes corresponde a uma lógica, que considera o orçamento de cada um e suas peculiaridades. O sistema conta com a participação da União, Municípios, Estados e Distrito Federal, que atuam como meças em um sistema para o fornecimento de saúde. No momento que uma decisão judicial determina que um ente exerça a atividade que originalmente era obrigação de outro, começa a desorganização do sistema.

Um dos elementos que demonstram a desorganização causada pelas decisões judiciais na seara da saúde é o preço pago pelo governo pelos materiais ou serviços prestados. Um ente estatal quando efetua a compra de um produto a faz através de um processo licitatório, em que o preço e as condições são analisados para que caiba no orçamento e para que supra as necessidades. Com um volume expressivo, com um valor correspondente ao preço pago na forma de atacado, ou seja, com valores menores que os pagos individualmente, as compras públicas são realizadas.

No momento de cumprir uma ordem judicial, que determina a entrega emergencial de um medicamento ou tratamento, o poder público quebra a lógica de licitação, de menor preço, de distribuição de responsabilidade entre os entes, e desorganizadamente, procura no mercado o objeto da determinação judicial. Isso aos poucos vai interferindo na forma de organização do Estado, a ponto de gerar uma desordem tão grande que prejudica a participação original daquele ente. E isto é apenas um exemplo de uma forma de desorganizar o sistema público. Nos últimos tempos é cada vez mais recorrente a objeção de que as decisões judiciais em matéria de medicamentos provocam a desorganização da Administração Pública.

\subsection{Quando o Judiciário deve interferir nas políticas públicas}

Diante do crescente número de ações judiciais que demandam por medidas na área da saúde, a atuação do Poder judiciário pode ser compreendida de várias formas. Entre conceder tudo o que é requerido ou indeferir qualquer pedido, há uma lógica que deve ser considerada.

É corrente a interpretação do texto constitucional que entende que este não confere limites para a efetivação do direito prestacional à saúde, em que a norma legal confere ao Judiciário o poder de conceder a cada jurisdicionado o direito a obter qualquer meio que necessite para resolução de problemas ligados a saúde. Esta forma de interpretação maximalista 
da Constituição colaborou para a ampliação da excessiva judicialização das relações que envolvem pedidos relacionados com a área da saúde.

Ocorre que as políticas públicas devem atender a coletividade, e não a todos individualmente considerados, e para determinar os limites para as decisões a serem tomadas, devemos partir da análise do caso concreto.

Uma demanda que envolve o direito à saúde deve ser avaliada considerando a origem da falta de políticas públicas para a situação dada, se se trata de um problema derivado da omissão absoluta em matéria de políticas públicas em saúde ou se é uma situação que envolve o não cumprimento de prestações em saúde.

Pode-se hoje perceber que os efeitos da atuação judicial no âmbito de algumas políticas sociais também acarretam a alteração do caráter democrático estabelecido, além de provocar a desorganização do sistema. Em muitas situações envolvendo direitos sociais, direito à saúde e mesmo fornecimento de medicamentos, o Judiciário poderá e deverá intervir. Tal constatação, todavia, não torna tal intervenção imune a objeções diversas, sobretudo quando excessivamente invasiva da deliberação dos outros Poderes.

Em que pese haver entendimentos variados sobre o tema, uma consideração importante e que serve de balizamento para a tomada de decisões na área da saúde foram aquelas explanadas pelo Supremo Tribunal Federal, quando da realização da Audiência Pública no 4/2009 que tratou do tema da judicialização da saúde.

As normas que tratam do direito à saúde, como o art. 196 da Constituição, conferem as diretrizes para a formulação e implementação das políticas públicas de saúde, definem parâmetros a serem seguidos, mas não determinam que medidas específicas devam ser tomadas. É neste espaço que reside a área de atuação do poder político do Executivo e do Legislativo, democraticamente escolhidos, e que poderão apontar os caminhos para que as diretrizes constitucionais sejam perseguidas.

Compreendemos que o Poder Executivo e o Poder Legislativo estabelecem o que é fornecido, em termos de direito prestacional à saúde. Nesse sentido, a conduta do Poder Executivo poderá variar entre a configuração material ou a omissão absoluta na configuração das políticas públicas de saúde. (CURY, 2016, p. 112)

Em situações em que há omissão absoluta do Poder Executivo, com a falta de previsão da medida nas políticas públicas de saúde, deverá o Judiciário agir e determinar a ação do 
Executivo, excepcionalmente, sem que se fale em intromissão na seara de outro Poder. Nestes casos a intervenção do Judiciário será legítima, pois deve fazer cumprir o estabelecido no art. 196 da Constituição através de medidas excepcionais. Se a legislação determina ação estatal em um determinado sentido, e esta ação não se concretiza, então o Judiciário atua para conferir efetividade a Constituição.

\footnotetext{
O maior grau de participação democrática, tanto do Poder Legislativo quanto do Poder Executivo, na concretização das políticas públicas de saúde, definindo ações e serviços a serem prestados aos indivíduos, com base nos arts. 196 e seguintes da $\mathrm{CF} / 88$, restringe a possibilidade de definição dessas prestações pelo Poder Judiciário na efetivação do direito prestacional à saúde. (CURY, 2016, p.113)
}

Assim, diante ocaso concreto, deve ser avaliado se existe uma política pública que contemple a situação exposta. Quanto mais os direitos são explicitados, quanto mais estabelecidas as formas como as medidas devem ser efetivadas, menor é a área de atuação do Judiciário.

Se existe a necessidade de um medicamento ou tratamento, e não há previsão dentro das políticas públicas para efetivação desta demanda, é evidente a omissão do Executivo. Deve, assim, ser analisado se o este adotou medidas para elidir determinada doença, se proporcionou aos usuários do sistema condições de acesso aos serviços nos termos do art. 196 da Constituição.

Pode-se exemplificar com situações bastante corriqueiras de pedidos judiciais de fornecimento de um determinado medicamento, sendo que o similar está disponível na rede pública.

Com isso, ao lidar com casos de omissão, é possível ainda dividir as situações em casos em que a medida recomendada não possui previsão, caso de um médico que prescreve medicamento fora da lista daqueles que são fornecidos (Rename), e em casos que são requeridas melhorias na prestação do serviço de saúde, caso de determinar quais especialistas deverão atuar na ampliação de determinado hospital.

Nas duas situações acima descritas, a solução é distinta: na primeira situação há uma omissão absoluta por parte do Executivo, pois existe a necessidade pelos usuários e o Estado não supre por não constar nas políticas públicas. Foi a situação que ocorreu quando determinada a obrigação do Executivo em fornecer medicamentos para tratamento de pessoas portadoras do 
HIV, onde havia a demanda e não havia uma política pública para tanto. A omissão por parte do Poder Executivo justifica a intervenção do Judiciário.

\begin{abstract}
A margem existente para a Administração Pública definir o conteúdo do direito prestacional à saúde não pode tornar-se uma barreira insuperável ao Poder Judiciário. Se há fatos e evidências que reconhecem a existência de uma determinada doença que possa gerar um dano à vida de um indivíduo sem condições financeiras de arcar com seu próprio medicamento/tratamento, é possível a intervenção do Poder Judiciário para a determinação do fornecimento. (CURY, 2015, p.115).
\end{abstract}

No caso de requerimento de melhorias na prestação de um serviço, como por exemplo, uma demanda de ampliação de leitos de determinado hospital, ou contratação de profissionais para determinadas especialidades, deve ser considerado se as políticas públicas adotam ações para melhoria das condições para a coletividade. Caso isso já ocorra, não há como o Judiciário intervir, pois o Estado está cumprindo o dever de prestar o serviço de saúde, e uma intervenção seria extrapolar a barreira entre os Poderes.

Se o Executivo possui uma política pública direcionada para melhorar as condições de atendimento na saúde, a intervenção do Judiciário nesta esfera também é ilegítima, pois a determinação constitucional foi respeitada, o Executivo cumpriu com sua parte e discricionariamente optou por uma forma de prestar a ação em saúde, e teve apenas que respeitar o limite orçamentário de restrição à atuação estatal. Não são raros os casos de ações judiciais que postulam medidas cujo poder público já fornece uma solução, porém de outra maneira. Se existe um meio e este foi escolhido como uma política pública para resolver estas questões, não cabe ao judiciário intervir.

Outra situação que é muito corrente nos tribunais são os casos de pedidos de fornecimento de medicamento ou tratamento de saúde em que as medidas já são previstas em políticas públicas, mas que de alguma forma não são cumpridas pelo Poder Executivo.

Diante desta situação, o Poder Judiciário deverá intervir para fazer com que uma política pública seja efetuada, ou seja, que uma lei seja cumprida. Esta possibilidade é observada em situações que paciente necessitam de determinado medicamento, este está na relação nacional de medicamentos (Rename), mas que por algum motivo não é fornecido. Esta é uma situação em que a atuação do Judiciário é legítima, pois trata-se de novamente, fazer com que o 
Executivo cumpra uma regra, independentemente de qualquer escolha político-administrativa do administrador.

Diante desta situação, é refutável tanto o argumento de discricionariedade, pois não cabe ao Poder Executivo avaliar a política pública que está sendo desrespeitada, bem como o argumento de falta de recursos, já que o fornecimento deste medicamento deveria estar previsto no orçamento. Assim, no momento que uma prestação do poder público é criada, vincula-se com uma obrigação legal, que não pode deixar de ser realizada através da justificativa da ausência de recursos.

\section{Conclusões}

A saúde como política pública no Brasil é bastante complexa, dada a diversidade de realidades, a influência de mercados com interesses nos pacientes/consumidores, ao território continental, a uma série de carências ocasionadas pela falta de outras políticas pública, enfim, é um tema que se depara com uma série de outras questões.

A forma como a saúde pública foi organizada, conferindo gratuidade e universalidade no atendimento através de um órgão que redireciona para os entes do Estado as atribuições de cada um, gerou uma série de possibilidades de haver a intervenção do Poder Judiciário.

Como o Poder Judiciário tem atuado de forma cada vez mais frequente na solução de problemas envolvendo a saúde pública, a sua forma de atuação também passou a ser objeto de análise. Com isso, a chamada judicialização da saúde passou a ser um tema recorrente em questões que tratam de políticas públicas. Esta forma de atuação jurisdicional é uma consequência da falta de uma política realmente efetiva, assim como pode ser considerada uma das causas da crise na saúde.

Desta forma, o tema é de suma importância para a compreensão do sistema estatal de distribuição de políticas sociais, e a sua análise deve ser realizada sob a perspectiva das políticas públicas. Somente assim é que decisões judiciais poderão colaborar com a efetiva distribuição de bem-estar social, que é o objetivo final das políticas públicas em geral.

\section{Referências Bibliográficas}


BAPTISTA, Tatiana Wargas de Faria. História da saúde pública no Brasil: a trajetória do direito à saúde. In MATTA, Gustavo; PONTES, Ana Lúcia, (Org.) Políticas de saúde: organização e operacionalização do Sistema Único de Saúde. Rio de Janeiro: Fiocruz. 2007. Disponível em: <http://www.retsus.fiocruz.br/upload/publicacoes/pdtsp_3.pdf>. Acesso em: 20 ago. 2016.

BRAUNER, Maria Claudia Crespo; CIGNACHI, Janaina Cristina Battistelo. O direito à saúde e o papel do poder judiciário: uma perspectiva acerca das dimensões constitucionais e das tutelas coletivas. In JURIS: Revista da Faculdade de Direito da FURG, v. 16, p.2948, 2011.

COSTA, Eder Dion De Paula; FLORES, Rodrigo Gomes. Judicialização da saúde no Brasil: porque para se levar o direito à saúde a sério deve-se também levar o sistema único de saúde à sério? In XXIV Congresso Nacional do CONPEDI - UFMG/FUMEC/Dom Helder Câmara, Direitos sociais, seguridade social e previdência social, Belo Horizonte, 2015.

COSTA, José Ricardo Caetano. Neoconservadorismo e direitos previdenciários: a (des)constituição dos direitos sociais previdenciários nas duas últimas décadas. In: Direito e Justiça Social a construção jurídica dos direitos de cidadania. Coordenado por Maria Claudia Crespo Brauner e Anderson Orestes Cavalcante Lobato. Rio Grande: Editora da Furg, p. $85-112,2015$.

MORIN, Edgar. Ciência com consciência. Rio de Janeiro: Bertrand, 2010.

SENNA, Mônica de Castro Maia e MONNERAT, Gisele Lavinas. O setor da saúde e os desafios da seguridade social brasileira. In: Trabalho e seguridade social: percursos e dilemas. Coordenado por Elaine Rossetti Behring e Maria Helena Tenório de Almeida. São Paulo: Cortez; Rio de Janeiro: FSS/UERJ, p.193-213, 2010. 
SOARES, Hector Cury. Os critérios imediatos para o controle jurisdicional do direito prestacional à saúde com base nas decisões do supremo tribunal federal entre 2009-2014. In JURIS: Revista da Faculdade de Direito da FURG, v. 26, p.109-128, 2016.

SOUZA, Jessé. A tolice da inteligência brasileira: ou como o país se deixa manipular pela elite. São Paulo: LeYa, 2015.

TANAKA, Oswaldo Yoshimi; OLIVEIRA, Vanessa Elias de. Reforma(s) e estruturação do Sistema de Saúde Britânico: lições para o SUS. Saúde soc., São Paulo, v.16, n.1, p.7-17, Apr. $2007 . \quad$ Disponível em:

$<$ http://www.scielo.br/scielo.php?script=sci_arttext\&pid=S0104-

12902007000100002\&lng=en\&nrm=iso>. Aceso em 20 mai. 2017. 